\title{
Prolonged Inhibition of Neutral Endopeptidase 24.11 by Sinorphan in Stroke-Prone Spontaneously Hypertensive Rats
}

\author{
Johannes-Peter Stasch, Andreas Knorr, Max Wegner, and Claudia Hirth-Dietrich
}

\begin{abstract}
The cardiovascular consequences of inhibition of the neutral endopeptidase 24.11 (NEP) with the orally active NEP inhibitor sinorphan were evaluated by determining long-term effects of the drug on hemodynamic, hormonal and structural parameters in stroke-prone spontaneously hypertensive rats (SHR-SP). Systolic blood pressure increased in young SHR-SP from $194 \pm 2$ to $266 \pm 7 \mathrm{mmHg}$, whereas in sinorphan $(30 \mathrm{mg} / \mathrm{kg}$ p.o. bid) treated animals systolic blood pressure increased only from $193 \pm 4$ to $229 \pm 4$ mmHg during the treatment period of 9 weeks. The increase in relative heart weight was also delayed. Plasma ANP was higher in the sinorphan group than in the controls. The results of a second study demonstrate a substantial improvement of cardiac pump function and ventricular hypertrophy in old SHR-SP with compromised cardiac function by long-term inhibition of NEP. Thirteen-month-old SHRSP were treated with sinorphan $(30 \mathrm{mg} / \mathrm{kg} \mathrm{p.o.} \mathrm{bid)} \mathrm{for} \mathrm{two} \mathrm{weeks.} \mathrm{At} \mathrm{the} \mathrm{end} \mathrm{of} \mathrm{experiment,} \mathrm{the} \mathrm{in-}$ crease in ANP plasma levels did not reach statistical significance, whereas plasma cGMP was higher in sinorphan treated animals than in controls. Left ventricular end-diastolic pressure was markedly elevated in controls and significantly lower in sinorphan treated animals. In addition, sinorphan reduced cardiac hypertrophy in these old SHR-SP. In conclusion, the results of the present studies demonstrate that long-term NEP inhibition with sinorphan has inhibitory effects on malignant hypertension and associated cardiac hypertrophy in young SHR-SP on a high-sodium diet. NEP inhibition substantially improves cardiac pump function and reduces ventricular hypertrophy of old SHR-SP with compromised cardiac function. (Hypertens Res 1995; 18: 137-143)
\end{abstract}

Key Words: atrial natriuretic peptide, neutral endopeptidase inhibitor, stroke prone spontaneously hypertensive rat, cardiac hypertrophy, congestive heart failure

Atrial natriuretic peptides (ANP), which are secreted by atrial myocytes in response to increased intravascular volume and atrial stretch, have potent natriuretic, diuretic, and vasorelaxant properties and suppress the renin-angiotensin-aldosterone system. ANP is cleared from plasma by ANP clearance receptors (ANP C receptors) and by enzymatic degradation by neutral endopeptidase 24.11 (NEP). It has been shown that inhibition of the NEP causes a blood pressure decrease in response to increased ANP plasma levels (1-4). Obviously, these interesting actions of ANP have led many investigators to speculate that NEP inhibitors could be valuable therapeutic tools for the treatment of disorders such as hypertension, renal failure and congestive heart failure (4-8). Indeed, most studies using NEP inhibitors have confirmed significant increases in plasma ANP (9-14); a few have not (15-17). However, data on the depressor effects of NEP inhibitors are conflicting. NEP inhibitors do not decrease blood pressure in animals with congestive heart failure $\left(10^{-12)}\right.$ or in those with chronic renal failure. With regard to hypertensive animals, NEP inhibition substantially decreased blood pressure in DOCA/salt rats (14-17) and in Dahl salt-sensitive rats, but not in spontaneously hypertensive rats (SHR) in acute experiments $(13,15,16,18-21)$.

Arterial hypertension is a major risk factor for damage of the brain, kidney and heart in humans. Spontaneously hypertensive rats and their strokeprone substrain (SHR-SP) have been employed widely as a model of human hypertensive disease. SHR-SP develop malignant hypertension accompanied by extensive end-organ damage, including malignant nephrosclerosis, cerebrovascular lesions, and brain infarctions (22-24). Dietary salt load in young SHR-SP has been shown to intensify hypertension and renal and cerebrovascular lesions (23$25)$. SHR-SP initially fail to suppress and later paradoxically increase renin secretion when fed a highsodium diet $(25,26)$. Morbidity and mortality are increased due to renal and cerebrovascular lesions in these rats and are associated with a rise in activity of the renin-angiotensin system $(25,26)$.

From the Bayer AG, Cardiovascular and Arteriosclerosis Research, Wuppertal, Germany.

Address for Reprints: Dr. JP Stasch at Bayer AG, Cardiovascular and Arteriosclerosis Research, D-42096 Wuppertal, Germany.

Received July 25, 1994; accepted in revised form October 28, 1994. 
Little is known with regard to the effects of chronic NEP inhibition in stroke-prone spontaneously hypertensive rats (SHR-SP). Here, we report the results of a preventive trial with the NEP inhibitor sinorphan $(4-8,29)$, which was administered orally to young SHR-SP on a high-salt diet $(8 \% \mathrm{NaCl})$ for 9 weeks. In a second experiment, sinorphan was administered for 2 weeks to aged SHR-SP with congestive heart failure. The aim of this study was to evaluate the cardiovascular consequences of inhibition of the neutral endopeptidase 24.11 (NEP) with the orally active NEP inhibitor sinorphan by determining long-term effects of the drug on hemodynamics, and on hormonal and structural parameters in SHR-SP.

\section{Material and Methods}

\section{Animals and Treatment}

Forty SHR-SP were obtained from the Central Animal Facilities of Bayer AG. They were housed under controlled conditions of light and temperature.

Study 1: At the age of 10 weeks, the animals were fed a high salt diet $(8 \% \mathrm{NaCl}$ in a commercial diet, Ssniff Versuchstierdiäten, Soest, Germany) and were treated with $30 \mathrm{mg} / \mathrm{kg}$ sinorphan orally by gavage at 8:00 a.m. and 4:00 p.m. for 9 weeks. Sinorphan was administered as a suspension in polyethylene glycol 400/carboxymethyl cellulose $(0.5 \%)$ solution $(\mathrm{v} / \mathrm{v}=10 / 90)$. The administration volume was 2 $\mathrm{ml} / \mathrm{kg}$ body weight. The controls received the vehicle. Systolic blood pressure was measured every week by the tail-cuff method in conscious animals, prewarmed in thermostatic cages at $37^{\circ} \mathrm{C}$. At the end of the study, all animals were weighed and killed by decapitation. Blood samples were collected after decapitation into prechilled EDTA tubes.

Study 2: Fifty-six-week-old male SHR-SP were used in this experiment and fed standard rat chow containing $0.4 \% \mathrm{NaCl}$. The blood pressure of these animals had already passsed its summit and was slowly declining. Systolic blood pressures were in the range of $180 \mathrm{mmHg}$. At the age of 56 weeks, more than $50 \%$ of the initial group of animals had already died. The animals were treated with 30 $\mathrm{mg} / \mathrm{kg}$ sinorphan orally by gavage at 8:00 a.m. and 4:00 p.m. The controls received vehicle only. After 14 days of treatment, animals were anesthetized with 3\% halothane in air. After completion of the hemodynamic measurements, the animals were bled from a carotid artery catheter. Blood samples were collected into prechilled EDTA tubes.

After thoracotomy, the kidneys and the hearts were removed and the ventricles isolated by cutting off the atria, pulmonary arteries, and aortas. The ventricles were opened, washed, blotted dry with filter paper, and weighed.

\section{Plasma Determinations}

Plasma renin activity (PRA) was determined by incubation of rat EDTA plasma with phenylmethylsulfonyl fluoride. The accumulated angiotensin I was measured with a commercially available radioimmunoassay kit (Sorin Biomedica, Saluggia, Italy).

For determination of cyclic GMP in plasma, an equal volume of ice-cold $10 \%$ trichloroacetic acid was added to the samples at $4^{\circ} \mathrm{C}$. After centrifugation the supernatant was extracted four times with water-saturated ether to remove the acid, lyophilized, redissolved in sodium acetate buffer, and assayed with a commercially available radioimmunoassay kit (IBL, Hamburg, Germany).

ANP in plasma was measured after extraction with $\mathrm{C}_{18}$-cartridges by a specific radioimmunoassay as previously described (28).

Plasma creatinine was determined by a spectrometric method (29), and plasma urea was determined by an enzymatic UV test (30).

\section{Renal Parameters}

In the last week of experiments, the rats were placed into metabolic cages for determination of renal excretion. Urinary sodium and potassium were determined by flame photometry (Laboratory Instruments, USA). Cyclic GMP in urine was measured with a commercially available radioimmunoassay kit (IBL, Hamburg, Germany).

\section{Hemodynamics}

For the measurement of left ventricular pressure, a micro-tip blood pressure catheter (Millar SPR-249) was inserted into the right carotid artery and advanced into the left ventricle. After placement of the catheter, a steady-state concentration of $0.8 \%$ halothane was applied for exactly $10 \mathrm{~min}$, and at least 10 cardiac cycles were registered at $250 \mathrm{~mm} / \mathrm{s}$ paper speed. Left ventricular pressure and its first derivative $(\mathrm{dp} / \mathrm{dt})$ were recorded simultaneously. End-diastolic pressure was taken at the point of time when the first derivative of left ventricular pressure began to rise above baseline. Each individual value is the mean of 10 cardiac cycles. After registration the catheter was removed and its baseline drift was recorded for correction of end-diastolic pressure. Control and treated animals were studied in a random order. Typical rates of rise of left ventricular pressure and end-diastolic pressure obtained in normotensive aged Wistar rats of $440 \mathrm{~g}$ body weight were $6,231 \pm 256 \mathrm{mmHg} / \mathrm{s}$ and $3.3 \pm 0.5$ $\mathrm{mmHg}(n=17)$, respectively.

\section{Statistics}

Differences between means were analyzed by Student's $t$-test after testing samples for normal distribution. Significant differences were assumed when $p<0.05$. Results are presented as means \pm SEM.

\section{Results}

Study 1

The development of systolic blood pressure in 10week-old SHR-SP on a high sodium diet could be delayed significantly by sinorphan treatment (30 $\mathrm{mg} / \mathrm{kg}$ p.o. bid). Systolic blood pressure increased in control animals from $194 \pm 2 \mathrm{mmHg}$ to $266 \pm 7$ $\mathrm{mmHg}$ during the observation period of 9 weeks 


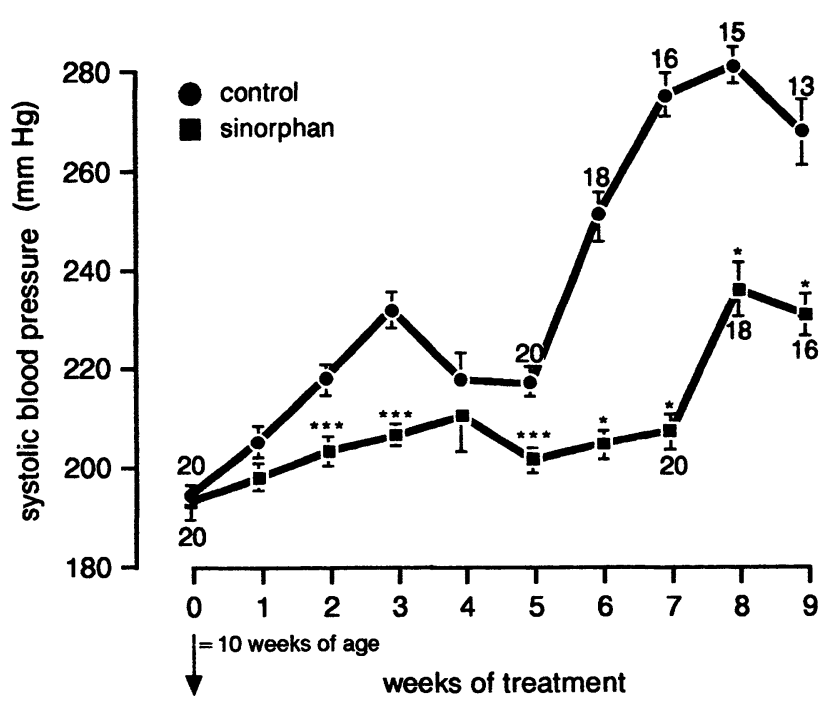

Fig. 1. Development of systolic blood pressure in sinorphan treated and untreated SHR-SP fed a high salt diet $(8 \% \mathrm{NaCl}$ ) for 9 weeks. Number over or under the curve shows number of surviving animals. Values are means \pm SEM. ${ }^{*} \mathrm{p}<0.05,{ }^{* * *} \mathrm{p}<0.005$ compared with values in untreated controls.

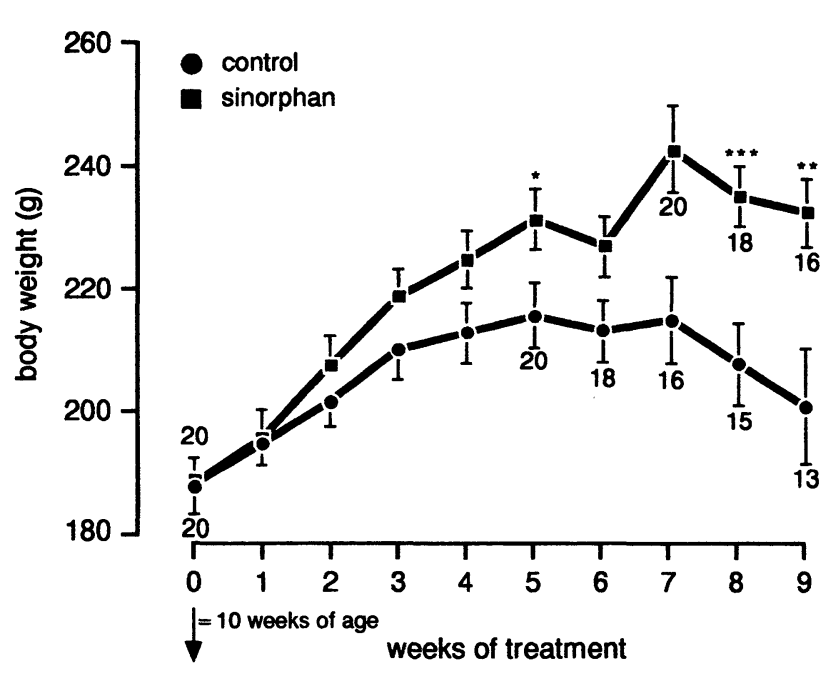

Fig. 2. Development of body weight in sinorphan treated and untreated SHR-SP fed a high salt diet ( $8 \% \mathrm{NaCl}$ ) for 9 weeks. Number over or under the curve shows number of surviving animals. Values are means \pm SEM. ${ }^{*} \mathrm{p}<0.05$, ${ }^{* *} \mathrm{p}<0.01, * * * \mathrm{p}<0.005$ compared with values in untreated controls.

Table 1. Study 1: The Effect of Long-Term Treatment (9 wk) with Sinorphan $(30 \mathrm{mg} / \mathrm{kg}$ p.o. bid) in Young SHR-SP on $8 \% \mathrm{NaCl}$ on Blood Pressure, Body Weight (BW), Heart Weight, Kidney Weight, and Mortality

\begin{tabular}{lcc}
\hline \multicolumn{1}{c}{ Variable } & Control & Sinorphan \\
\hline Blood pressure $(\mathrm{mmHg})$ & $266 \pm 6.7(13)$ & $229 \pm 4.2(16)^{\#}$ \\
Body weight $(\mathrm{g})$ & $201 \pm 9.4 \quad(13)$ & $233 \pm 5.5(16)^{* *}$ \\
Relative heart weight $(\mathrm{mg} / 100 \mathrm{~g} \mathrm{BW})$ & $475 \pm 14 \quad(13)$ & $422 \pm 4.9(16)^{* * *}$ \\
Relative kidney weight $(\mathrm{mg} / 100 \mathrm{~g} \mathrm{BW})$ & $1,061 \pm 49 \quad(13)$ & $921 \pm 20 \quad(16)^{*}$ \\
Mortality & $7 / 20$ & $4 / 20$ \\
\hline
\end{tabular}

Values are means $\pm \operatorname{SEM}(n) .{ }^{*} p<0.05,{ }^{* *} p<0.01,{ }^{* * *} p<0.005,{ }^{\#} p<0.001$ compared with values in untreated controls.

(Fig. 1). In the sinorphan treated animals, systolic blood pressure increased from $193 \pm 4 \mathrm{mmHg}$ to 229 $\pm 4 \mathrm{mmHg}$ during the treatment period. In contrast, sinorphan did not decrease systolic blood pressure significantly in 10-week-old SHR-SP and 19-weekold salt-loaded SHR-SP given 10,30 and $100 \mathrm{mg} / \mathrm{kg}$ p.o. in single-dose experiments (data not shown).

After 9 weeks, $80 \%$ of the rats receiving sinorphan, but only $65 \%$ of the controls, were still alive (Fig. 1, Table 1). Higher morbidity in controls than in sinorphan treated rats was also suggested by body weight. Following 5 weeks of a high salt diet, untreated rats during the last 5 weeks of the experiment lost body weight, whereas the sinorphan treated rats did not (Fig. 2, Table 1). Relative heart weights and relative kidney weights were significantly lower in the sinorphan group (Table 1).

Table 2 summarizes basic plasma variables in the controls and sinorphan treated rats at the end of the 9-week experimental period. ANP plasma levels increased significantly during sinorphan treatment.
Although statistical analysis did not show any significant differences, the plasma renin activity and plasma aldosterone concentration tended to be higher in the control SHR-SP group than in the sinorphan group. Plasma urea was significantly lower and hematocrit significantly higher in the sinorphan group. Plasma creatinine and plasma sodium were comparable in the two groups, as show in Table 2.

In the 9th week of treating the SHR-SP on a high salt diet with sinorphan, indices of renal function were measured. No significant effects were observed with respect to diuresis, natriuresis and kaliuresis, whereas cyclic GMP excretion was significantly elevated (Table 3 ).

\section{Study 2}

After 14 days of sinorphan treatment of old SHRSP with end-stage hypertension, plasma ANP tended to increase, but no statistically significant difference was found (Table 4). Similarly, no significant differences in plasma angiotensin I and plasma 
Table 2. Study 1: The Effect of Long-Term Treatment $(9$ wk) with Sinorphan $(30 \mathrm{mg} / \mathrm{kg}$ p.o. bid) in Young SHR-SP on 8\% NaCl on Atrial Natriuretic Peptides (ANP), Renin Activity (PRA), Angiotensin I, Aldosterone, Urea, Sodium and Creatinine in Plasma and Hematocrit

\begin{tabular}{|c|c|c|}
\hline Variable & Control & Sinorphan \\
\hline ANP (pg/ml) & $265 \pm 22 \quad(10)$ & $455 \pm 25 \quad(16)^{\#}$ \\
\hline PRA (ng/ml/h) & $15.3 \pm 2.6$ & $13.2 \pm 1.6$ \\
\hline Angiotensin I (ng/ml) & $2.3 \pm 0.3$ & $2.2 \pm 0.3$ \\
\hline Aldosterone $(\mathrm{pg} / \mathrm{ml})$ & $128 \pm 26$ & $94 \pm 26$ \\
\hline Urea plasma $(\mathrm{mmol} / \mathrm{l})$ & $9.2 \pm 1.0$ & $6.9 \pm 0.2(16)^{*}$ \\
\hline Sodium (mmol/l) & $132 \pm 1.0$ & $133 \pm 0.7$ \\
\hline Creatinine $(\mu \mathrm{mol} / \mathrm{l})$ & $45 \pm 2.0$ & $45 \pm 1.1$ \\
\hline Hematocrit $(\%)$ & $35 \pm 1.5 \quad(13)$ & $39 \pm 0.9(16)^{*}$ \\
\hline
\end{tabular}

Values are means $\pm \operatorname{SEM}(n) .{ }^{*} p<0.05,{ }^{\#} p<0.001$ compared with values in untreated controls.

Table 3. Study 1: The Effect of Long-Term Treatment (9 wk) with Sinorphan (30 $\mathrm{mg} / \mathrm{kg}$ p.o. bid) in Young SHR-SP on 8\% NaCl on Urine Volume, Sodium, Potassium, and Cyclic GMP Excretion. Collecting Period $6 \mathrm{~h}$

\begin{tabular}{lcc}
\hline \multicolumn{1}{c}{ Variable } & Control & Sinorphan \\
\hline Diuresis $(\mathrm{ml} / \mathrm{kg} / \mathrm{h})$ & $11.8 \pm 0.9(13)$ & $12.8 \pm 0.8(16)$ \\
Natriuresis $(\mu \mathrm{mol} / \mathrm{kg} / \mathrm{h})$ & $1,878 \pm 150(13)$ & $2,046 \pm 144(16)$ \\
Kaliuresis $(\mu \mathrm{mol} / \mathrm{kg} / \mathrm{h})$ & $330 \pm 24 \quad(13)$ & $372 \pm 30 \quad(16)$ \\
cGMP excretion $(\mathrm{nmol} / \mathrm{kg} / \mathrm{h})$ & $4.2 \pm 0.9(13)$ & $9.3 \pm 1.5(16)^{* *}$ \\
\hline
\end{tabular}

Values are means $\pm \operatorname{SEM}(n) .{ }^{* *} p<0.01$ compared with values in untreated controls.

Table 4. Study 2: Influence of 14 Days of Treatment with Sinorphan (30 mg/kg p.o. bid) in Old SHR-SP on ANP, cGMP, Angiotensin I, Renin Activity (PRA) in Plasma Body Weight (BW), Relative Heart Weight, and Relative Kidney Weight

\begin{tabular}{|c|c|c|}
\hline Variable & Control & Sinorphan \\
\hline $\mathrm{ANP}(\mathrm{pg} / \mathrm{ml})$ & $471 \pm 67$ & $612 \pm 122(11)$ \\
\hline cGMP (pmol/ml) & $27.2 \pm 4.6$ & $41.8 \pm 4.8(11)^{* * *}$ \\
\hline Angiotensin I (ng/ml) & $2.8 \pm 0.6$ & $2.1 \pm 0.3$ \\
\hline $\operatorname{PRA}(\mathrm{ng} / \mathrm{ml} / \mathrm{h})$ & $11.7 \pm 3.3$ & $9.2 \pm 0.9$ (11) \\
\hline Body weight (g) & $332 \pm 3$ & $334 \pm 5$ \\
\hline Relative heart weight (mg/100 g BW) & $460 \pm 14 \quad(12)$ & $420 \pm 6$ \\
\hline Relative kidney weight (mg/100 g BW) & $802 \pm 16 \quad(12)$ & $801 \pm 16 \quad(12)$ \\
\hline
\end{tabular}

Values are means $\pm \operatorname{SEM}(n) .{ }^{*} p<0.05,{ }^{* * *} p<0.005$ compared with values in untreated controls.

Table 5. Study 2: Influence of 14 Days of Treatment with Sinorphan (30 $\mathrm{mg} / \mathrm{kg} \mathrm{p.o}$. bid) in Old SHR-SP on Left Ventricular (LV) Rate of Rise, LV Systolic Pressure, LV End-Diastolic Pressure, and Heart Rate

\begin{tabular}{|c|c|c|}
\hline Variable & Control & Sinorphan \\
\hline $\mathrm{LV}$ rate of rise $(\mathrm{mmHg} / \mathrm{s})$ & $6,880 \pm 209(12)$ & $7,431 \pm 226(11)$ \\
\hline LV systolic pressure $(\mathrm{mmHg})$ & $171 \pm 4$ & $166 \pm 5$ \\
\hline $\mathrm{LV}$ end-diastolic pressure $(\mathrm{mmHg})$ & $24.3 \pm 0.7$ & $15.9 \pm 2.0(11)^{\#}$ \\
\hline Heart rate (beats/min) & $312 \pm 8 \quad(12)$ & $297 \pm 9$ \\
\hline
\end{tabular}

Values are means $\pm \operatorname{SEM}(n) .{ }^{\#} p<0.001$ compared with values in untreated controls.

renin activity were noted, although values tended to be lower in sinorphan treated rats (Table 4). However, cGMP in plasma, as a marker for ANP involvement, was increased in animals treated with sinorphan.

Heart rate, left ventricular systolic pressure, and left ventricular rate of rise in systolic pressure were unaffected by sinorphan (Table 5). Left ventricular end-diastolic pressure, however, was markedly elevated in control animals, exceeding $20 \mathrm{mmHg}$ (Table 5). Young normotensive Wister rats reach values of $4 \mathrm{mmHg}$ under the experimental conditions used (data not shown).

Aged SHR-SP treated with sinorphan had signif- 
Table 6. Study 1: Influence of 14 Days of Treatment with Sinorphan $(30 \mathrm{mg} / \mathrm{kg}$ p.o. bid) in Old SHR-SP on Urine Volume, Sodium, Potassium, and Cyclic GMP Excretion. Collecting Period 24 h

\begin{tabular}{|c|c|c|}
\hline Variable & Control & Sinorphan \\
\hline Diuresis $(\mathrm{ml} / \mathrm{kg} / \mathrm{h})$ & $2.8 \pm 0.4 \quad(12)$ & $2.5 \pm 0.2$ \\
\hline Natriuresis $(\mu \mathrm{mol} / \mathrm{kg} / \mathrm{h})$ & $230 \pm 16$ & $249 \pm 12$ \\
\hline Kaliuresis $(\mu \mathrm{mol} / \mathrm{kg} / \mathrm{h})$ & $341 \pm 20$ & $277 \pm 16 \quad(12)^{*}$ \\
\hline cGMP excretion $(\mathrm{nmol} / \mathrm{kg} / \mathrm{h})$ & $2.2 \pm 0.3$ & $5.4 \pm 0.6(12)^{\#}$ \\
\hline
\end{tabular}

Values are means $\pm \operatorname{SEM}(n) .{ }^{*} p<0.05,{ }^{\#} p<0.001$ compared with values in untreated controls.

icantly reduced end-diastolic pressures (Table 5). In addition, treatment with sinorphan also reduced the increased heart weights of these rats (Table 4).

In the second week of treating the old SHR-SP with sinorphan, indices of renal function were measured. No significant effects were observed with respect to diuresis and natriuresis, whereas kaliuresis and cyclic GMP excretion was significantly elevated (Table 6).

\section{Discussion}

The cardiovascular consequences of NEP inhibition with sinorphan were evaluated by determining longterm effects of the drug on hemodynamic, hormonal, and structural variables in two experimental animal models of hypertension: young SHR-SP on a high-sodium diet and aged SHR-SP with congestive heart failure. SHR-SP develop malignant hypertension accompanied by extensive end-organ damage, including malignant nephrosclerosis, cerebrovascular lesions, and brain infarctions (22-24). Dietary salt load in young SHR-SP has been shown to intensify hypertension and renal and cerebrovascular lesions (23-25). Morbidity and mortality increased due to renal and cerebrovascular lesions in these rats, associated with a rise in the activity of the reninangiotensin system $(25,26)$. Plasma levels of ANP in SHR-SP are elevated and may reflect a compensatory response of the rat to maintain normal blood pressure and plasma volume. We surmised that sinorphan, by preventing degradation of ANP, would potentiate the activity of the endogenous hormone and thereby prevent the development of hypertension and associated cardiac hypertrophy. The development of systolic blood pressure in the 10 -week-old stroke-prone spontaneously hypertensive rats on a high sodium diet could be delayed significantly by sinorphan treatment. It was previously demonstrated that chronic administration of the NEP inhibitor SCH 34826 prevents hypertension in $\mathrm{NaCl}$-sensitive spontaneously hypertensive rats (SHR-S) by increasing endogenous ANP (31). These NaCl-sensitive SHR-S received SCH 34826 for 4 weeks beginning immediately before the initiation of an $8 \% \mathrm{NaCl}$ diet. SCH 34826 had no effect on blood pressure in SHR-S fed a normal diet (31).

These results were also underlined by studies providing evidence that chronic administration of the NEP inhibitors SCH 34826 and SCH 42495 in adult SHR with established hypertension for 1 month produced no significant changes in blood pressure
$(32,33)$. These findings agree with our results that chronic oral administration of a NEP inhibitor prevents $\mathrm{NaCl}$-sensitive hypertension in SHR and support the hypothesis that $\mathrm{NaCl}$-sensitive hypertension in SHR-S and SHR-SP is an ANP-deficient state.

Long-term treatment with sinorphan in SHR-SP on a high-sodium diet not only prevented the development of hypertension: it also prevented the associated cardiac and renal hypertrophy. There is some evidence that the reductions in cardiac and kidney mass are independent of the hemodynamic changes in these rats. It was previously reported that chronic treatment for 1 month with the NEP inhibitors SCH 34826 and SCH 42495 in adult SHR with manifest hypertension reduced cardiac mass and the amount of fibrotic tissue present in the left ventricle despite the lack of antihypertensive activity $(32,33)$.

It has been proposed that ANP acts as a physiological antagonist of the renin-angiotensin-system $(1-3,28)$. The left ventricular myocytes and the cells within the kidney contain detectable amounts of angiotensin II that may act as a trophic growthpromoting factor. Thus, local inhibition of angiotensin II by enhanced ANP activity in ventricles and kidneys may exert a protective and antihypertrophic influence on cardiac myocytes and kidney cells. This interpretation, relying on a possible interaction between ANP and angiotensin II, does not rule out other mechanisms, still unexplored, that may have played a part in determining changes in cardiac hypertrophy. NEP hydrolyzes numerous substances including brain natriuretic peptide, bradykinin, and substance $p(34)$. The role of these peptides in ventricular and kidney hypertrophy remains to be elucidated.

At the end of treatment, in the plasma compartment no significant decrease in renin activity, angiotensin I and aldosterone concentration was observed in the sinorphan group despite elevated ANP plasma levels. A slight protective effect on kidney function is reflected in the reduced urea concentration in plasma in the sinorphan group. Treatment with sinorphan led to a significant improvement in the overall health of SHR-SP on a high sodium diet as demonstrated by a continuous gain in body weight and an increased survival rate.

These results of the second study demonstrate a substantial improvement of cardiac pump function and ventricular hypertrophy in old SHR-SP with comprised cardiac function by two-week inhibition of the neutral endopeptidase 24.11 with sinorphan. 
At the time treatment commenced, the SHR-SP were in a stage of disease, characterized by declining arterial pressure, marked increases in end-diastolic filling pressure, cardiac hypertrophy, and high plasma ANP. Compared with normotensive Wistar Kyoto rats of similar age, plasma ANP in the old SHR-SP was elevated five-fold (35). Also, basal plasma renin activity was high. Similar pathological signs have been observed in rats with congestive heart failure after myocardial infarction (36).

The marked reduction in end-diastolic pressure obviously lowered cardiac load, because heart weights were substantially reduced in spite of the short duration of treatment. Sinorphan might have lowered end-diastolic pressure through both a reduction in pre- and afterload and circulating volume, because ANP increases venous distensibility (37), can reduce total periperal resistance (38), and, at least acutely, produces volume contraction (39). This occurred although systolic blood pressure was not reduced.

We found no sustained natriuretic effect after sinorphan. However, neither chronic enkephalinase inhibition nor ANP have been shown to be persistently natriuretic or diuretic $(40-42)$. This is presumably so, because chronic ANP is natriuretic only in chronically hypervolemic states $(43,44)$. Other characteristic signs of ANP action, such as an increase in plasma and urinary cGMP as well as a reduction in plasma renin activity were noted in this experiment $(1-3,28,45)$.

In conclusion, the results of the present studies demonstrate that long-term NEP inhibition with sinorphan has inhibitory effects on malignant hypertension and associated cardiac hypertrophy in young SHR-SP on a high-sodium diet and produces substantial improvements in cardiac pump function and ventricular hypertrophy in old SHR-SP with compromised cardiac function.

\section{Acknowledgement}

The authors wish to thank Mr. G. Birk, Mrs. C. Diederichs, Mr. R. Hartkopf, Mrs. Y. Keim, Mr. M. Olzen, Mrs. S. Ruppert, and Mrs. B. Verwohlt for their excellent technical assistance and Mrs. R. Quabeck for secretarial help.

\section{References}

1. Cantin $\mathbf{M}$, Genest $\mathrm{J}$ : The heart and the atrial natriuretic factor. Endocr Rev 1985; 6: 107-127.

2. Baxter JD, Lewicki JA, Gardner DG: Atrial natriuretic peptide. Biotechnology 1988; 6: 529-546.

3. Atlas SA, Maack T: Atrial natriuretic factor, in Windhager EE (ed): Handbook of Physiology. Vol. 2. New York, Oxford, Academic Press, 1992, pp15771673.

4. Schwartz JC, Gros C, Lecomte JM, Bralet J: Enkephalinase (EC 3.4.24.11) inhibitors. Protection of endogenous ANF against inactivation and potential therapeutic applications. Life Sci 1990; 47: 12791297.

5. Lecomte JM, Baumer P, Lim C, et al: Stereoselective protection of exogenous and endogenous atrial natriuretic factor by enkephalinase inhibitors in mice and humans. Eur J Pharmacol 1990; 179: 65-73.

6. Lefrancois P, Clerc G, Duchier J, et al: Antihypertensive activity of sinorphan. Lancet 1990; 336: 307-308.

7. Dussaule JC, Michel C, Peraldi MN, et al: Inhibition of neutral endopeptidase stimulates renal sodium excretion in patients with chronic renal failure. Clin Sci 1993; 84: 31-39.

8. Kahn JC, Patey M, Dubois-Rande JL, et al: Effect of sinorphan on plasma atrial natriuretic factor in congestive heart failure. Lancet 1990; 335: 118-119.

9. Lafferty HM, Gunning $M$, Silva P, Zimmermann $\mathrm{MB}$, Brenner BM, Anderson S: Enkephalinase inhibition increases plasma atrial natriuretic peptide levels, glomerular filtration rate, and urinary sodium excretion in rats with reduced renal mass. Circ Res 1989; 65: 640-646.

10. Margulies KB, Cavero PG, Seymour AA, Delaney NG, Burnett JC: Neutral endopeptidase inhibition potentiates the renal actions of atrial natriuretic factor. Kidney Int 1990; 38: 67-72.

11. Cavero PG, Margulies KB, Winaver J, Seymour AA, Delaney NG, Burnett JC Jr: Cardiorenal actions of neutral endopeptidase inhibition in experimental congestive heart failure. Circulation 1990; 82: 196-201.

12. Tikkanen I, Helin K, Tikkanen T, et al: Elevation of plasma atrial natriuretic peptide in rats with chronic heart failure by SCH 39370: a neutral metalloendopeptidase inhibitor. J Pharmacol Exp Ther 1990; 254: 641-645.

13. Hirata $\mathrm{Y}$, Matsuoka $\mathrm{H}$, Hayakawa $\mathrm{H}$, et al: Role of endogenous atrial natriuretic peptide in regulating sodium excretion in SHR: effects of neutral endopeptidase inhibition. Hypertension 1991; 17: 1025-1032.

14. Shepperson NB, Barclay PL, Bennett JA, Samuels GMR: Inhibition of neutral endopeptidase (EC 3.4.24.11) leads to an atrial natriuretic factor-mediated natriuretic, diuretic and antihypertensive response in rodents. Clin Sci 1991; 80: 265-269.

15. Sybertz EJ, Chiu PJS, Vemulapalli S, et al: $\mathrm{SCH}$ 39370 , a neutral metalloendopeptidase inhibitor, potentiates biological response to atrial natriuretic factor and lowers blood pressure in deoxycorticosterone acetate-sodium hypertensive rats. Eur J Pharmacol Exp Ther 1989; 250: 624-631.

16. Sybertz EJ, Chiu PJS, Vemullapalli S, Watkins R, Haslanger MF: Atrial natriuretic factor-potentiating and antihypertensive activity of SCH 34826: an orally active neutral metalloendopeptidase inhibitor. Hypertension 1990; 15: 152-161.

17. Seymour AA, Norman JA, Asaad MM, et al: Possible regulation of atrial natriuretic factor by neutral endopeptidase 24.11 and clearance receptors. J Pharmacol Exp Ther 1991; 256: 1002-1009.

18. Hirata Y, Suzuki E, Hayakawa H, et al: Mechanisms of the natriuretic effects of neutral endopeptidase inhibition in Dahl salt-sensitive and salt-resistant rats. $J$ Cardiovasc Pharmacol 1994; 23: 283-290.

19. Seymour AA, Swerdel JN, Fennell SA, Druckman SP, Neubeck R, Delaney NG: Potentiation of the depressor responses to atrial natriuretic peptides in conscious SHR by an inhibitor of neutral endopeptidase. J Cardiovasc Pharmacol 1989; 14: 194-204.

20. Seymour AA, Fennell SA, Swerdel JN: Potentiation of renal effects of atrial natriuretic factor-(99-126) by SQ 29,072. Hypertension 1989; 14: 87-97.

21. Trapani AJ, Beil ME, Cofé DT, et al: Pharmacological profile of CGS 24128: a potent long-acting inhibitor of neutral endopeptidase 24.11. J Cardiovasc 
Pharmacol 1994; 23: 358-364.

22. Okamoto K, Yamori Y, Nagaoka A: Establishment of the stroke-prone spontaneously hypertensive rat (SHR). Circ Res 1974; 34/35 (suppl I):I143-I145.

23. Nagaoka A, Shino A, Inotsuka H: Relationship between hypertension and cerebrovascular lesions in stroke-prone hypertensive rats. Jpn Heart J 1978; 19: 604-605.

24. Stasch JP, Kazda S, Luckhaus G, Knorr A, Garthoff B, Hirth-Dietrich C: Protection against hypertensive cardiovascular damage by dihydropyridine calcium antagonists, in Bruschi G, Borghetti A (eds): Cellular aspects of hypertension. Berlin-Heidelberg, Springer-Verlag, 1991, pp135-147.

25. Volpe M, Camargo MJF, Mueller FB, Campbell WG, Sealey JE, Pecker MS: Relation of plasma renin to end-organ damage and to protection of $\mathrm{K}$ feeding in stroke-prone hypertensive rats. Hypertension 1990; 15: 318-326.

26. Camargo MJF, von Lutterotti N, Campbell WG, et al: Control of blood pressure and end-organ damage in maturing salt-loaded stroke-prone spontaneously hypertensive rats by oral angiotensin II receptor blockade. J Hypertens 1993; 11: 31-40.

27. Bralet J, Mossiat C, Lecomte JM, Charpentier S, Gros C, Schwartz JC: Diuretic and natriuretic response in rats. Eur J Pharmacol 1990; 179: 57-64.

28. Stasch JP, Hirth-Dietrich C, Kazda S, Neuser D: Role of endogenous ANP on endocrine function investigated with a monoclonal antibody. Peptides 1990; 11: 577-582.

29. Bartels H, Böhmer M, Heierli C: Serum Kreatininbestimmung ohne Enteiweissen. Clin Chim Acta 1972; 37: 193-197.

30. Gutmann I, Bergmeyer HU: Bestimmung von Harnstoff, Glutamat-Dehydrogenase als Indikatorenzym, in Bergmeyer HU (ed): Methoden der Enzymatischen Analyse, 3rd Edition, Vol. II, Weinheim, Verlag Chemie, 1974, pp1842-1846.

31. Jin H, Mathews C, Chen YF, et al: Effects of acute and chronic blockade of neutral endopeptidase with $\mathrm{SCH} 34826$ on $\mathrm{NaCl}$-sensitive hypertension in spontaneously hypertensive rats. Am J Hypertens 1992; 5: 210-218.

32. Monopoli A, Ongini E, Cigola E, Olivetti G: The neutral endopeptidase inhibitor, SCH 34826, reduces left ventricular hypertrophy in spontaneously hypertensive rats. J Cardiovasc Pharmacol 1992; 20: 496-504.

33. Monopoli A, Forlani A, Ongini E: Chronic inhibition of neutral endopeptidase reduces left ventricular hypertrophy without changing blood pressure in spontaneously hypertensive rats. J Hypertens $1991 ; 9$ (suppl 6): S246-S247.

34. Wilkins MR, Unwin RJ, Kenny AJ: Endopeptidase-
24.11 and its inhibitors: potential therapeutic agents for edematous disorders and hypertension. Kidney Int 1993; 43: 273-285.

35. Stasch JP, Kazda S, Hirth C, Morich F: Role of nisoldipine on blood pressure, cardiac hypertrophy, and atrial natriuretic peptides in spontaneously hypertensive rats. Hypertension 1987; 10: 303-307.

36. Chien Y, Barbee RW, MacPhee AA, Frohlich ED, Trippodo NC: Increased atrial natriuretic factor (ANF) secretion after volume expansion is preserved in rats with heart failure. Abstract 70. Council for High Blood Pressure Research, 41st Annual Fall Conference Oct 13-16, 1987, New Orleans.

37. Ando SI, Imaizumi $T$, Harada S, Hirooka $Y$, Takeshita A: Atrial natriuretic peptide increases human capillary filtration and venous distensibility. $J$ Hypertens 1992; 10: 451-457.

38. Volpe M, Sosa RE, Müller FB, et al: Differing hemodynamic responses to atrial natriuretic factor in two models of hypertension. Am J Physiol 1986; 250 (Heart Circ Physiol 19): H871-H878.

39. Simchon S, Manger WM, Carlin RD, et al: Salt-induced hypertension in Dahl salt-sensitive rats. Hemodynamics and renal responses. Hypertension 1989; 13: 612-621.

40. Watkins RW, Vemulapalli S, Chiu PJS, et al: Atrial natriuretic factor potentiating and hemodynamic effects of SCH 42495: a new, neutral metalloendopeptidase inhibitor. Am J Hypertens 1993; 6: 357368.

41. Garcia R, Thibault G, Gutkowska J, Hamet P, Cantin $\mathrm{M}$, Genest $\mathrm{J}$ : Effect of chronic infusion of synthetic atrial natriuretic factor (ANF 8-33) in conscious two-kidney, one-clip hypertensive rats. Proc Soc Exp Biol Med 1985; 178: 155-159.

42. Cachofeiro V, Schiffrin EL, Thibault G, Cantin M, Garcia R: Effect of chronic infusion of atrial natriuretic factor on glomerular and vascular receptors in spontaneously hypertensive rats. J Hypertens 1989 ; 7: 335-342.

43. Garcia R, Gutkowska J, Genest J, Cantin M, Thibault G: Reduction of blood pressure and increased diuresis and natriuresis during chronic infusion of atrial natriuretic factor (ANF Arg 101-Tyr 126) in conscious one-kidney, one-clip hypertensive rats. Proc Soc Exp Biol 1985; 179: 539-545.

44. Blaine EH, Heinel LA, Schorn TW, Marsh EA, Whinnery MA: The character of the atrial natriuretic response: pressure and volume effects. $J$ Hypertens 1986; 4: S17-S24.

45. Stasch JP, Hirth C, Kazda S, Wohlfeil S: The elevation of cyclic GMP as a response to acute hypervolemia is blocked by a monoclonal antibody directed against atrial natriuretic peptides. Eur $J$ Pharmacol 1986; 129: 165-168. 